\title{
Brand management practices in emerging country firms - exploring the patterns of variation and its impact on firm performance
}

by

Ekrem Tatoglü, Sunil Sahadev ${ }^{b}$, Mehmet Demirbag $^{c}$

aprofessor, Ibn Haldun University, School of Business, Basaksehir, Istanbul, 34494, Turkey. Email: ekrem.tatoglu@ihu.edu.tr

${ }^{\text {b} P r o f e s s o r, ~ U n i v e r s i t y ~ o f ~ S a l f o r d, ~ T h e ~ C r e s c e n t, ~ S a l f o r d, ~ M a n c h e s t e r, ~ M 5 ~ 4 W T, ~ U n i t e d ~}$ Kingdom. E-mail: s.sahadev@salford.ac.uk

'Professor, Chair in International Business, University of Essex, Essex Business School, Southend Campus Elmer Approach Southend-on-Sea, SS1 1LW, United Kingdom. E-mail: mdemirc@essex.ac.uk

\#Corresponding author:

Professor Ekrem Tatoglu,

Ibn Haldun University, School of Business,

Basaksehir, 34494,

Istanbul

Turkey

Tel: +90-212-6920212

E-mail: ekrem.tatoglu@ihu.edu.tr 


\section{Brand management practices in emerging country firms - exploring the patterns of variation and its impact on firm performance}

Firms in emerging countries often face different sets of challenges in developing their brand management strategies. Drawing on the dynamic capabilities view, the present study examines brand management practices among firms in an emerging country. Drawing on a survey of 224 firms in Turkey, the study first aims to segment firms in terms of their adoption level of brand management practices and then relate them to their overall firm and brand performances. A three-cluster solution emerging from a K-means cluster analysis reveals that firms show significant differences with respect to both performance dimensions. The findings of the study also provide evidence to the view that brand management practices add to the dynamic capabilities of emerging country firms. Finally, the study concludes with practical implications and avenues for future research.

Keywords: Brand management practices, dynamic capabilities, emerging countries, Turkey. (JEL: M30, M31) 


\section{Introduction}

Schultz and Barnes (1999:36) define brand management as "the process of creating, coordinating and monitoring interactions that occur between an organization and its stakeholders such that there is consistency between an organization's vision and stakeholders". Brand management also constitutes a central organizational competence that must be understood, nurtured and developed (Louro/Cunha 2001). This idea of brand management can be linked to the concept of 'brand orientation' that treats brand as a strategic resource instead of merely being an unconditional response to customer needs and wants (Urde 1999). Urde (1999) argues that brand provides the firm with a framework within which the customer needs can be satisfied. Similarly, brand is an important firm resource that can serve as a strategic reference point. It can shape business development by realizing an alignment between the capabilities of the firm and the external environment. Brand management is also related to the concept of brand strategy that "emphasizes the entrenched continuity and connectedness of the firm with its external environment" (Abimbola/Kocak 2007:422).

The extant literature on brand management is rich and extensive (Heding et al., 2008) and covers a wide array of perspectives and ideas (Louro/Cunha, 2001). A unifying framework that brings together these different perspectives is always much valued. To this end, the brand report card (BRC) developed by Keller (2000) is an extremely useful and logical combination of diverse streams of thought in the domain of brand management. Keller (2000) developed the idea of $\mathrm{BRC}$ as a comprehensive list of factors or traits that define the parameters of a firm's brand management applications. The BRC comprises of ten factors which, taken together, has the potential to define the health of a firm's brand management strategy and practices. However, despite the immense practical utility of the BRC to measure and benchmark firm strategies, use of it has been limited in theory. This is despite the existence of a major stream of literature that considers the brand orientation of firms (see Hirvonen et al. 2013; Anees-ur-Rehman et al. 2016 for short reviews). The BRC concept, though strongly related to the idea of brand orientation, attempts to report the existing practices regarding brand management of a firm. Brand orientation which has been defined as the "mindset that considers brands as a strategic resource' (Urde 1999), is actually more of a reflection of 
strategic intentions while $\mathrm{BRC}$, on the other hand, attempts to explain the existing brand management practices (BMPs) in a firm. Hence to understand the impact of branding strategies on firm performance it would be more meaningful to consider the current BMPs of the firm.

Consequently, building on prior literature (Keller 2000; Keller/Lehman, 2006; Berthon et al. 2008; Keller/Lehman, 2009) and also based on the dynamic capabilities view, this study aims to provide new insights into the implementation of BMPs in the context of an emerging country (EC) market. The context of an EC market to understand BMPs of firms' has actioned several calls for research on marketing practices on EC firms (e.g. Sheth 2011; Hilmerson/Jansson 2012; Kearny 2012). As Burgess and Steenkamp (2006) argue, research studies that focus on EC markets immensely contribute to the growth of knowledge in marketing. There is also an increasing realization that lessons learnt from doing business in EC markets can be transferred to developed economies as well as to other developing countries (Enderwick 2009). Thus, researchers have been emphasizing the need for studying how firms in EC markets develop strategies to acquire relevant capabilities to enhance their performance (Zahra et al. 2006; Bruton/Lau 2008; Malik/Kotabe 2009; Erdogmus et al. 2010; Kearney 2012).

The study attempts to make several contributions to the existing literature. First by using the BRC framework to segment firms, the study helps to better understand and describe the patterns in the adoption of BMPs. Previous studies have not used the BRC framework to segment firms despite the comprehensive nature of BRC and its strong linkages to practice. This will help in explaining patterns and benchmark firms in terms of adoption of BMPs thereby contributing to the extant literature in brand management as a strategy. Second, the study attempts to contribute to the literature that positions brand management as an important component of the dynamic capability of firms by drawing out the performance outcomes of BMPs. Previous studies that have attempted to explore the outcomes of brand orientation have shown mixed results (e.g. Laukkanen et al. 2013; Reijonen et al. 2015). By considering a comprehensive scale to measure brand performance, this study actions the call made by 
Anees-ur-Rehman et al. (2016) to conduct quantitative studies with large samples to establish the linkages between brand orientation and performance. Thirdly, by considering the BMPs of firms in an emerging country, the study expands the geographic scope of the discourse on BMPs and attempts to generalize the validity of the framework. This study, in a way, actions the call made by King et al. (2013) and Anees-ur-Rehman et al. (2016) to conduct brand orientation studies in eastern cultures to validate the basic premises of brand orientation.

The study has the following two main objectives: First, based on Keller's (2000) BRC framework, it captures the pattern in variation of BMPs among firms in an EC market in order to develop firm configurations. Second, we explore the differences in performance with respect to the various firm configurations based on the adoption level of their BMPs.

The remainder of this study is organized as follows. The next section provides a review of the relevant literature on both marketing practices and brand management in EC markets and also how branding strategy contributes to the dynamic capabilities of the firm to justify our hypotheses. The third section presents the research methods followed by the results of the study. Discussion and managerial implications are provided in the final section.

\section{Literature review}

The study contributes to the existing knowledge of branding strategy and its relationship to the overall performance of a firm in the context of an EC market. To highlight the contribution of this study, we need first to consider how branding strategy sits in the context of the overall corporate strategy of a firm.

According to Srivastava et al. (1998), the market-based assets of a firm are either relational or intellectual and add value to the firm by either adding value to tangible assets or by exploiting the benefits of networks. The brand equity of a firm is considered as a relational asset as it is the outcome of relationships (Srivastava et al. 1998), while the branding strategy of a firm is an intellectual asset of the firm as it is a manifestation of the unique knowledge and expertise that the firm has developed concerning the tastes, preferences, attitudes and beliefs of its customers. Previous studies have shown how a credible brand influences the performance of 
firms (Yeung and Ramaswamy 2008; Wong et al. 2013; Ng et al. 2014), thereby underlying the status of a brand as an important resource base for the firm. Needless to say, a well conceived branding strategy and brand management program are essential for a firm to develop a credible brand. Several authors have acknowledged the status of branding strategy as an important asset to the firm that should drive the overall strategy of the firm (Capon et al. 2001; Douglas et al. 2001; Wong/Merrilees 2008).

\subsection{Marketing practices and brand management in emerging countries}

Over the past decade, a large number of studies focusing on marketing in EC markets have been published. Most of these studies essentially focus on issues related to the entry of developed country multinational enterprises (MNEs) to EC markets or consumer adoption of multinational brands in these country markets (Walters/Samiee 2003; London/Hart 2004; Khanna et al. 2005; Meyer/Tran 2006; Xie/Boggs 2006; Türkyilmaz/Özkan 2007). However, marketing strategies of firms within ECs have received relatively less research attention. In a seminal paper, Sheth (2011) explores the central themes and issues relevant to marketing in ECs. According to Sheth (2011:166), ECs are slowly "evolving from the periphery to the core of marketing practice", hence it is imperative to "contend with their unique characteristics and question our existing practices and perspectives, which have been historically developed largely in the context of industrialized markets". He asserts that many beliefs that are fundamental to marketing, such as market segmentation, market orientation, and brand equity, are at odds with the realities of EC markets. He further adds that the need for revisiting the fundamental premises of marketing in ECs is brought out by the following five fundamental characteristics of ECs: (i) market heterogeneity; (ii) socio-political governance; (iii) unbranded competition; (iv) chronic shortage of resources; and (v) inadequate infrastructure. Some of these propositions have been justified in prior studies. For instance, Ellis (2006) found that the relationship between marketing orientation and performance is confirmed only in large developed countries, but not in developing countries. Studies on branding strategies in ECs, therefore, assume importance as customers typically have relatively less awareness or comprehension of brands in these markets (Sheth 2011). 
While numerous studies consider branding from the consumer perspective in the context of ECs, research on firm-level brand management strategies in ECs is still in a nascent stage and subject to evolution. The existing studies are scattered across different domains without a unifying theme. Interestingly, except for a notable few (Jit Singh Mann/Kaur 2013), studies that focus on brand management strategies of EC firms within their home markets are somewhat rare with most focusing on MNEs operating in those countries (Meyer/Tran 2006; Li/Zhou 2010; Erdogmus et al. 2010). This strand of research deals largely with the standardization versus adaptation debate in BMPs. Another line of research that has attracted much attention recently involves the BMPs of EC firms operating in developed countries (Duysters et al. 2009; Omar et al. 2009; Tsai/Eisingerich 2010).

\subsection{Conceptualizing brand management practices}

BMPs encompass all the practices adopted by firms to enhance the value of their brands. The span of BMPs in terms of the decision-making domains within an organization is vast as they encompass all activities that could create lasting impressions on stakeholders (Shultz/Barnes 1999). In their seminal work, Louro and Cunha (2001:853) define the brand management paradigm as "a deep-seated way of seeing and managing brands and their value, shared by the members of an organizational community marked by a common culture". Since the idea of 'brand management practices' encompasses a broad domain of activities, it is possible to identify and compare a number of constructs in the extant literature that encapsulate this idea. While these constructs no doubt have individual definitions, they are closely linked to BMPs and can be considered as falling within the broad realm of brand management strategy.

Keller's (2000) BRC framework is a highly robust and comprehensive framework as it consolidates and captures most of the diverging traits of the BMPs (Ewing/Napoli 2005). The robustness of this framework were testified by previous studies that adopted this framework in a range of sectors like non-profit charities (Ewing/Napoli 2005); franchise branding (Pitt et al. 2003) and SMEs (Berthon et al. 2008). Notably, this framework is able to capture the dynamic and evolving nature of brand management in a firm by balancing the aspects of continuity and change. The ten traits measured by BRC are: (1) customer benefit delivery, (2) relevance to 
customers, (3) pricing strategy, (4) correct positioning, (5) consistency in communications messages, (6) clear brand architecture, (7) using the full range of communications, (8) customer understanding, (9) support and investment, and (10) tracking sources of brand equity. Keller's BRC framework has been used by several authors to analyze the extent of BMP adoption (Pitt et al. 2003; Ewing/Napoli 2005; Berthon et al. 2008).

Brand orientation is a concept that has close similarities with BMPs. Baumgarth (2010:656) defines a brand orientation as:

"a specific type of marketing orientation, which is distinguished by the high relevance accorded to branding by top management. It also implies a strongly systematic approach to brand management characterized by an offer that is relatively constant, consistent and relevant to the buyer and clearly differentiated from the competition".

Basically, brand orientation implies treating branding activities at the strategic level, not at the tactical level. Hence, essentially, brand orientation is a reflection of the primacy of the brand to the overall strategy of the firm. In line with the idea of brand orientation, BMPs are also rooted in the strategy of the firm and influence the key decisions at the operational level to reflect an urge to enhance the value of the brand. As Keller (2000:54) observes: "building and development of strong brands necessitates that the brand is properly supported, and that support is sustained in the long run".

A brand management system (BMS) is defined as "a set of any systems, organizational structure, or culture of a firm supporting brand building activities" (Lee et al. 2008:849). Santos-Vijande et al. (2013) have developed a BMS scale comprising three dimensions: brand orientation, internal branding, and strategic brand management. The concept of BMS is based on the 'strategy as practice' paradigm (Dunes/Pras 2013). While Lee et al. (2008) conceptualized brand orientation as part of the BMS, there has been considerable criticism to this view (Dunes/Pras 2013) in that brand orientation is seen more as an organizational culture or a shared state of mind in the organization that drives the organization's strategy (Urde et al. 2013; Dunes/Pras 2013). 
In a similar vein, Chen et al. (2011) have developed the idea of integrated brand management' to describe a systematic business process in which a firm actively engages in initiating, developing, and maintaining its brand equity. According to their conceptualization, an integrated brand management process should comprise of distinct stages of implementation, planning and control.

All four constructs (viz. brand management practices, brand orientation, brand management system and integrated brand management) described above are interrelated; have similarities; and draw upon the common idea of brand as a strategic asset to the firm which needs to be nurtured and promoted. These constructs also support the belief that brand management is a part of the overall strategy development process of the firms. It can also be argued that these constructs capture the same nomological domain. Studies which have adopted these constructs also highlight their multi-dimensional nature. In fact, all these constructs have been operationalized using different sub-dimensions. It is in this context that the BRC approach to capture the BMPs proves to be more robust and comprehensive than brand orientation, BMS or integrated brand management. The BRC concept captures more dimensions and reflects more closely the actual practice of brand management in organizations.

\subsection{Brand management practices as a dynamic capability of firms}

An important offshoot of the resource based view of a firm is the dynamic capabilities model. While a firm may possess several resources, it requires a complex set of capabilities to effectively and systematically utilize these resources. The importance of such capabilities has been acknowledged in several studies. Newbert (2007), conducting a meta-analysis of empirical research on the resource based view of the firm, argues in favor of capabilities rather than resources, in terms of relevance and the potential impact on performance. As Merrilees et al. (2011:369) assert, "resources per se cannot do anything... What is important is the capacity to utilize resources effectively, that is, a capability". A dynamic capability is defined as "the firm's ability to integrate, build, and reconfigure internal and external competencies to address rapidly changing environments" (Teece et al. 1997:516). Dynamic capability has also been defined as a pattern of collective activity through which an 
organization modifies its operating routines (Zollo/Winter 2002). Accordingly, dynamic capabilities are expected to emerge from learning and adaptation of routine practices. Further, as Winter (2003) stresses, building dynamic capabilities involves significant long term commitment of specific resources.

BMPs involve setting up a system for designing interactions with the main stakeholder groups in a way that enhances the value of the brand (Schultz/Barnes 1999). According to Morgan et al. (2009:286), "brand management capability concerns the systems and processes used to develop, grow, maintain, and leverage a firm's brand assets". This capability is built on the strengths of several cross functional capabilities such as marketing research, product design, product management, pricing and marketing communication (Aaker 1991; Andriopoulos/Gotsi 2000). Within the organization it is both a collective activity and also involves significant long term commitments. In fact, as Morgan (2012:107) argues, brand management capability can be considered as cross-functional capabilities that "are more complex and higher order than specialized capabilities since they involve integrating a number of different specialized capabilities". According to Morgan (2012), the three cross functional marketing capabilities are CRM, brand management and new product development. This view is strongly supported by Matanda and Ewing (2012), who argue that as the top management of a firm develops and implements a branding strategy to reconfigure existing resources and capabilities in a turbulent environment, branding can be viewed as a dynamic capability.

Support for considering the brand management capability of a firm as part of its portfolio of dynamic capabilities can also be found in the strategic management literature. For instance, Teece (2007) categorized dynamic capabilities of firms as falling into sensing, seizing or reconfiguring capabilities. Based on this framework, Ellonen et al. (2009) identify the brand management capability of a firm to have all the characteristics of 'seizing capability'. Further, several studies have also considered activities linked to brand management as dynamic capabilities (Helfat/Winter 2011; Santos-Vijande et al. 2013). 


\subsection{Linking brand management practices with firm performance}

It is well acknowledged in strategic management literature that dynamic capabilities of firms tend to increase firm performance and profitability (Zott 2003; Arthurs/Busenitz 2006; Wu 2007; Morgan et al. 2009; Protogerou et al. 2012). Hence the association between BMPs - a component of dynamic capabilities of a firm and performance -can be inferred.

However, the relationship between brand management and performance may not be very straightforward. Though firms could devote considerable resources for brand building, its impact on performance - both overall operational/financial performance as well as brand performance - is contingent upon several firm-related and contextual factors (Hirvonen et al. 2013). Contextual factors such as the competition in the environment, customer profile as well as internal factors like age and size of the firm could also have an impact (Sinkula 1994; Reijonen 2010).

Prior studies that have adopted relevant constructs like brand orientation and BMS have attempted to explore their effect on firm performance. They, however, produced mixed results. While Brïdson and Evans (2004), Napoli (2006) and Baumgarth (2010) note a strong empirical relationship between brand orientation and market performance, in their multicountry study, Laukkanen et al. (2013) do not find any significant relationship between brand orientation and performance. Instead, they find a significant positive relationship between brand orientation and brand performance of firms in both Hungary and Finland. In a similar vein, some of the earlier studies focusing on the relationship between BMS and firm performance (Lee et al. 2008; Dunes/Pras 2013; Santos-Vijande et al. 2013) note a significant and positive link between BMS and firm performance. Chen et al. (2011) also find a positive and significant relationship between integrated brand management and performance.

Overall performance is defined as the performance of the firm across several dimensions such as operations, capacity utilization and finance. Adoption of BMPs could influence performance in a number of direct and indirect ways. For instance, it could help in developing a loyal customer base that eventually leads to a predictable demand pattern which could, in turn, help in smoothing out the production cycle and capacity utilization in manufacturing and 
service firms. BMPs could also help in charging a premium and thus enhance the profitability of the firm (Doyle 1989). This leads to the following hypothesis.

Hypothesis 1: Brand management practices are positively related to a firm's overall performance such that firms that place greater emphasis on brand management practices achieve greater overall performance than firms that place lesser emphasis on brand management practices.

Wong and Merrilees (2008) define brand performance as the success of the brand in the market. This would involve several dimensions such as brand value and number of brands with the dominant position in the market. While adoption of BMPs is expected to lead to superior brand practices in general, several moderating variables may also make a difference. For instance, in an industry where all the players adopt sophisticated BMPs, the impact of BMPs on brand performance may not be very prominent. Further, in industries where consumers are not very brand conscious BMPs might not have much impact. However, BMPs definitely have an overall impact in developing the brand image, brand awareness and thereby brand equity regardless of the branding context. Adoption of BMPs can create and internal organizational environment where branding becomes a strategic activity. This can enhance the importance of brand related activities with specific objectives and metrics set for achieving brand performance related targets. Thus, we expect that:

Hypothesis 2: Brand management practices are positively related to a firm's brand performance such that firms that place greater emphasis on brand management practices achieve better brand performance than firms that place lesser emphasis on brand management practices.

\section{Research methods}

\subsection{Sample and data collection}

Turkey was chosen as the survey setting for this study because of its clear position as an EC market (Tatoglu et al. 2016). There are fundamental differences between emerging country markets and mature markets - most essentially, the absence of strong regulatory agencies as well as shared cultural values (Anil et al. 2014; Erguncu/Yildirim 2014). Firms operating in 
such environments will all be developing strategies to survive and thrive under similar circumstances. While Turkey is a dynamic market with a growing economy, Turkey is considered to be very appropriate to validate models initially adopted in western societies (Demirbag et al. 2014; Cifci et al. 2016). The sampling frame for our survey was based on the members' list of TOBB (The Union of Chambers of Commerce, Industry, Maritime Trade and Commodity Exchanges of Turkey, available at http://www.tobb.org.tr), which provides an industrial database containing approximately 40,000 firms registered to any of 10 Chambers of Industry, 19 Chambers of Trade and 64 Chambers of Industry and Trade in Turkey. Based on a random sampling selection procedure, a total of 1,000 firms operating in a wide variety of industries was generated and constituted the sample for our survey.

The survey questionnaire, which was originally developed in English, was translated from English to Turkish and then re-translated into English by a second party to ensure accuracy in translation. This process of 'back translation' is useful in identifying misinterpretations and misunderstandings before the questionnaire is administered. To further ensure the authenticity of the translation, two bilingual researchers were used in tandem to compare the back translated English and Turkish versions of the questionnaire and make any necessary changes. Then, a questionnaire and a covering letter were posted to the general manager of each firm with a letter requesting that the general manager, or his/her senior executive in charge of brand management within the organization, should complete it. During the period of AprilMay in 2014, a total of 241 questionnaires were returned after one reminder, of which 224 were usable (an effective response rate of $22.4 \%$ ). Such a response rate is satisfactory, given the nature of the questionnaire and the type of potential respondent.

A test for non-response bias for the mail survey was conducted by comparing the first wave of survey responses to the last wave of survey responses (Armstrong/Overton 1977). The test results indicated no significant difference in the responses between early and late respondents ( $p>0.1$ ). Hence, no response bias was evident. ANOVA tests were also used to compare the responding firms across the main characteristics of the sample such as industry type and geographical location and, again, showed no systematic differences $(\mathrm{p}>0.1)$. 
ANOVA tests were used to examine the differences among means for the respondent categories. No significant differences $(p>0.1)$ were detected. Given the level of responsibility of respondents, the findings provide a good reflection of senior management's views on the scope and nature of BMPs.

The characteristics of the questionnaire respondent firms are summarized in Table 1.

\section{[Insert Table 1 here]}

\subsection{Measurement of variables}

The data were gathered via a cross-sectional mail survey using a questionnaire. Our questionnaire was drawn from Keller's (2000) BRC, which includes various aspects of BMPs. The BRC scale used in this study is composed of 33 items constituting a total of 10 BMPs. These 10 BMPs are as follows: BMP 1: 'Brand delivers benefits customers truly desire'; BMP 2: 'Brand stays relevant'; BMP 3: 'Pricing strategies based on perceptions of value'; BMP4: 'Brand is properly positioned'; BMP 5: 'Brand is consistent'; BMP 6: 'Brand portfolio and hierarchy make sense'; BMP 7: 'Brand uses full repertoire of marketing activities to build equity'; BMP 8: 'Brand managers understand what the brand means to consumers'; BMP 9: 'Brand is given proper support and it is sustained over the long run'; and BMP 10: 'Company monitors sources of brand equity'. Each item was measured through a five-point scale $(1=$ 'to a very little extent' to $5=$ 'to a very great extent'). In an earlier work, Berthon et al. (2008) also successfully applied the same measures to examine the nature and scope of brand management within the small and medium enterprises (SME) context.

Overall performance was measured as the mean measure of the responses given to a set of 11 measures of performance. The respondents were asked to identify their firm's performance on a five-point scale $(1=$ 'definitely worse' to $5=$ 'definitely better') for each of these 11 performance indicators in the following manner: "over the last three years, how has your company performed in terms of the following performance criteria?" These measures are namely operating efficiency, quality, after sales service, sales, profitability, market share, new 
product development, brand awareness, financial performance, customer satisfaction, and human resources management.

Brand performance was measured as the mean measure of the responses provided to a list of seven measures underlying a firm's brand performance. Relying, again, on a five-point scale $(1=$ 'definitely worse' to $5=$ 'definitely better'), the respondents were requested to identify their company's brand performance over the last three years for each of the following seven indicators: the number of brands with a dominant place in domestic markets; the number of brands with a dominant place in global markets; the percentage of revenues accounted for by branded products/services; the number of brands generating $80 \%$ of total revenues; the percentage of brand budget within total revenues; ranking in brand image; and relative value of brand.

\section{Results}

\subsection{Measurement model validation}

The convergent and discriminant validity of the measurement model comprising of 37 observed variables and 10 latent constructs were assessed through a confirmatory factory analysis (CFA) procedure implemented through AMOS. Since the initial CFA model did not show adequate levels of fit, observed variables with a standardized loading of less than 0.5 were initially eliminated. Two items were dropped from BMP 2 (brand stays relevant); one item was deleted from BMP 3 (pricing strategies based on perception of value) and another from BMP 7 (brand uses full repertoire of marketing activities to build equity). A content validity check of the deleted items indicated that the remaining items would definitely capture the original dimensions of the latent constructs. After eliminating these four items, the measurement model indicated adequate levels of fit $\left[\chi^{2} /\right.$ d.f. $=2.1, \quad$ CFI $=0.9, \quad I F I=0.9$, RMSEA=0.07; SRMR =0.05]. The convergent validity was assessed by considering the standardized loading of all the constructs as well as the average variance extracted (AVE). The standardized loadings for all items were above 0.5 and significant $(\mathrm{p}<0.01)$ and the AVE was also above 0.5 . The values for convergent validity are shown in Table 2 .

[Insert Table 2 here] 
Discriminant validity was checked using the methodology suggested by Anderson and Gerbing (1988). In this approach, the chi-square goodness of fit values were computed for pairs of latent constructs, first without any constraints in the inter-construct correlation and then with the inter-construct correlation fixed to one. If the difference in the $\chi^{2}$ values were found to be significant, discriminant validity between the two latent constructs was established. As shown in Table 3, we compared the $\chi^{2}$ values for 45 pairs of constructs and found that for all pairs of constructs, the $\chi^{2}$ value difference was significant $(\mathrm{p}<0.01)$ at one degree of freedom. The minimum difference in $\chi^{2}$ value was 10.7 between BMP 4 and 10; while the maximum difference was 125.4 between BMP 1 and 7. The average difference was 47.35. Hence the measurement scales have both convergent and discriminant validity. The reliability of the scales was assessed through Cronbach alpha coefficient which was found to be more than 0.7 for all the constructs, as shown in Table 2, exhibiting a satisfactory level of construct reliability (Nunnally, 1978).

\section{[Insert Table 3 here]}

\subsection{Cluster analysis}

As the main objective of the study is to examine the pattern of variation between EC firms in terms of their emphasis on BMPs, it is necessary to explore systematic variation between the firms across each of the ten dimensions. To this end, a K-means cluster analysis was undertaken to segment the sample firms. The cluster analysis enables to categorize firms in terms of their extent of adoption of BMPs such that firms falling in a particular group are as homogeneous as possible in their brand management applications. As Ketchen and Shook (1996) contend, cluster analysis helps in potentially rich descriptions as it allows for inclusion of diverse dimensions in developing firm configurations (Harrigan 1985; Ketchen et al. 1997).

Several studies have applied cluster analysis methods to compare firms across different attributes. To exemplify, De Jong and Marsili (2006) cluster small firms into four groups in terms of their innovative capabilities; Deniz and Suares (2006) categorize Spanish family owned firms with regard to their corporate social responsibility orientations; Berghman et al. (2006) classify Dutch firms into four clusters in terms of their marketing knowledge 
accumulation capabilities; Leiponen and Drejer (2007) group firms in Finland and Denmark into five different categories based on their innovation activities; Fillipetti (2011) clusters firms in terms of their innovation modes.

Before conducting the cluster analysis, mean values of each of the 10 BMPs was computed. Deciding on the number of a priori clusters requires considerable judgement and effort as there are no universally acceptable parameters to judge the suitability of ' $n$ ' cluster solution versus 'n-1' cluster solutions. In this study, we broadly followed the process suggested by Harrigan (1985) to arrive at the appropriate number of clusters. Initially, we tested 3-, 4- and 5-cluster solutions. In order to arrive at the optimum number of clusters, based on Harrigan (1985), we examined the F-values associated with the variables entered in each of the cluster solutions. The 3-cluster solution was found to produce higher F-values for all 10 variables except in the case of BMP 1 (that too only in the case of a 4-cluster solution compared to the 3-cluster solution). Further, in terms of cluster membership the only difference between the 4-cluster solution and the 3-cluster solution was that one of the clusters (cluster 1) from the 3-cluster solution was split into two separate clusters in the 4-cluster solution while it was found to be intact as one single cluster in the 3-cluster solution. The other two clusters (cluster 2 and cluster 3) remained unchanged with the same composition of firms in both the 3-cluster and 4cluster solutions. For the purpose of interpretation, the two separate clusters produced by splitting cluster 1 in the 4-cluster solution did not make any sense as each of the clusters had fewer number of firms in comparison to the one single cluster 1 produced by the 3 -cluster solution. The 3-cluster solution was, therefore, much more meaningful and more robust than the 4-cluster solution and we, therefore, decided to choose the 3-cluster solution. Hence, based on both Harrigan (1985) and the need for parsimony, a 3-cluster solution was finalized.

Tables 4 and 5 support a three-way classification of firms based on the extent and success of their BMPs. The final cluster centers from K-means cluster analysis prove that approximately $15 \%$ of the sample firms which fall in Cluster 1 have the lowest values for BMPs, while $40 \%$ of the firms have medium values and $45 \%$ of the firms have the highest values. Along with the support of the ANOVA results, the sample firms can be divided into three clusters or groups 
based on their adoption level of BMPs: (i) Cluster 1: low-BMP; (ii) Cluster 2: medium-BMP; and (iii) Cluster 3: high-BMP. The final cluster centers are shown in Table 4. Table 5 reveals the ANOVA results, attesting the statistical validity of the clustering solution.

\section{[Insert Tables 4 and 5 here]}

The high-BMP group comprises firms which have high values for the adoption of BMPs. On a five-point scale, they have mean values of more than 4.5 for any of the 10 BMPs. These firms tend to place much emphasis on their brands and engage in great effort to constantly nurture their brands. The medium-BMP group comprises nearly $40 \%$ of the total sample of firms and has mean values ranging between 3.52 and 4.38 for any of the 10 BMPs. These firms, while giving sufficient care for their brands, do not seem to consider brand management to be their highest priority. The low-BMP group, on the other hand, has mean values ranging between 2.17 and 3.81. Compared to the other two groups, the firms in the low-BMP group appear to provide much less emphasis on BMPs towards building or nurturing their brands.

In the next step, the overall profile of the clusters was assessed by cross tabulating the cluster membership of firms with their size and ownership category, as shown in Table 6. Chi-square tests indicated significant values between a profile variable and cluster category. In terms of firm size, some significant association was found $\left(\chi^{2}=8.27, \mathrm{p}<0.05\right)$ among BMP clusters in that nearly $16 \%$ of the high-BMP firms were SMEs while the percentages of SMEs in the lowand medium-BMP firms were $26.7 \%$ and $34.5 \%$, respectively. Hence, the high-BMP cluster had a higher percentage of large size firms than medium- and low-BMP clusters. Approximately $84 \%$ of all large size firms were in the high-BMP cluster with only $73.3 \%$ of large size firms being in the low-BMP cluster. In terms of the ownership pattern of sample firms there was, again, a significant association with the cluster membership $\left(\chi^{2}=5.78, \mathrm{p}<0.1\right)$. Low- and medium-BMP clusters had more Turkish firms which accounted for nearly $80 \%$ and $78 \%$ of both clusters, respectively. In contrast, the proportion of Turkish firms in the highBMP cluster was only $63 \%$. In a similar vein, approximately $37 \%$ of all foreign owned firms were in the high-BMP cluster with only $20 \%$ being in the low-BMP cluster. These findings, in 
general, indicate that large and foreign firms tend to place relatively more emphasis on BMPs when compared to local Turkish firms.

\section{[Insert Table 6 here]}

\subsection{BMP and firm performance}

In order to test the study's hypotheses, ANOVA tests were undertaken in order to examine the variation between three groups of firms in terms of the adoption level of BMPs and the following two performance variables: (i) overall performance and (ii) brand performance. Table 7 presents the results of ANOVA tests. The results from Table 7 show that the overall performance significantly differs across the three clusters of firms in that both high-BMP and medium-BMP firms have significantly higher mean values of overall performance $(p<0.01)$ as compared to low-BMP firms. This finding tends to confirm Hypothesis 1. Similarly, Table 7 shows that brand performance significantly differs across the three clusters of firms $(\mathrm{p}<0.01)$ with firms in the high-BMP cluster having significantly higher levels of brand performance relative to those firms in the medium- and low-BMP clusters. This result also provides support for Hypothesis 2. In Table 8, we show the post-hoc tests with the low-BMP segment as the control group. The Dunnett's t criterion shows the nature of the difference between the groups, further supporting the hypotheses.

\section{[Insert Tables 7 and 8 here]}

\section{Discussion and implications}

The study has attempted to investigate the adoption level of BMPs within EC firms and segmented the sample firms in terms of their use of BMPs. The study shows that, in general, firms can be classified into three segments: (i) a segment comprising of firms which place high emphasis on BMPs; (ii) a segment comprising of firms which place a medium level of emphasis on BMPs; and (iii) a segment comprising of firms which place low emphasis on BMPs. This three-way classification is both important and interesting from a theoretical point of view. In their study of Swedish firms, Gromark and Melin (2011) derive a 4-cluster solution to describe segments of firms which differ in terms of their brand orientation. These clusters show, also, distinct differences with respect to their financial profitability. However, 
the interpretation of these four clusters proved to be very difficult. The present study, on the other hand, generates a clearer and logical clustering solution that enhances the understanding of the differences in branding strategy among firms.

The results concerning the relationship between BMPs and firm performance is also significant in understanding the role of BMPs on firm performance. Hence, this study develops a foundation for further research in BMPs and their effect on firm value. Previous studies adopting similar constructs broadly reflecting the notion of BMPs (viz. brand orientation, brand management systems and integrated brand management) have attempted to relate them directly to the performance of the firm (Brïdson/Evans 2004; Napoli 2006; Lee et al. 2008; Baumgarth 2010; Chen et al. 2011; Laukkanen et al. 2013; Santos-Vijande et al. 2013). However, in these studies, the independent variables (i.e., brand management system, integrated brand management or brand orientation) were typically collapsed into only a single dimension, even though it is acknowledged that the independent variables, in fact, comprise multiple dimensions. In this study, first, by using the BRC, a larger and more comprehensive profile of branding strategy dimensions are employed; second, instead of collapsing these 10 dimensions into a single dimension, the firms are grouped based on a clustering algorithm that captures the variations in all 10 dimensions. Therefore, we are able to examine the impact of branding strategy on firm performance in a more comprehensive and robust manner.

Another theoretical contribution involves the validation of Keller's (2000) BRC framework in measuring the adoption level of BMPs within an EC context. As far as we are aware, this is the first study that has empirically validated the BRC framework using a rigorous empirical method. Future studies could base their measurement model on the basis of the results generated by this study. Given the comprehensive and exhaustive nature of this framework, adoption of the BRC will extend discussions on brand strategy in a more nuanced and comprehensive manner. Future studies could also compare the BRC framework across sectors as well as among firms of different sizes. Finally, future studies could also independently verify the significance of each of the 10 components of the BRC in determining the performance of firms. 


\subsection{Managerial implications}

In terms of managerial practice, this study provides insights for environmental scanning and strategy development. The idea of a three-way classification of firms in terms of their BMPs helps in building competitor profiles and capability mapping of firms. This will assist managers in developing competitor analysis prior to designing a marketing strategy in practice. The study also shows that firms which place greater emphasis on branding strategy, as reflected in the high scores on the BRC, also perform well. This provides encouragement for brand managers when they request greater allocation of resources for brand management in the marketing budgets of firms. This also supports the need to give more importance to a brand based organization of functions and placing a long term interest in brand building. While most firms are already involved in brand building, due to short-term considerations, firms could deviate from the brand building strategy which could result in sub-optimal results. This study underlines the significance of brand management and branding strategy in generating better performance for firms. At another level, this study legitimizes the possible adoption of the BRC framework as a managerial tool for measuring the effectiveness of a firm's branding strategy as well as benchmarking it against those of its rivals.

\subsection{Limitations and future research}

While the present study provides useful insights to the link between brand management applications and firm performance in EC firms, its limitations should also be acknowledged. Perhaps the most serious limitation of this study was its narrow focus on a single host country setting, thus precluding the generalization of findings to other EC markets. Future studies could compare the results of this study by considering samples from other EC country environments such as Latin America and Asia. Likewise, it would be equally useful in future studies to examine other EC and developed country combinations in order to develop a more coherent picture. Further, the study compares the relationships by taking into account a sample composed of different industries within Turkey, while this increases the generalizability of the results, focusing on a single industry would allow controlling for the effect of industry sector. The collection of data from a single respondent in each firm might be a cause for possible 
response bias. Collecting data from multiple informants and conducting longitudinal research would help researchers to address this common method bias problem. A caution should, therefore, be exercised when interpreting the results. Future studies may also integrate moderator variables into the model, such as degree of internationalization, competitive intensity and export orientation.

We also need to recognize the apparent merits of more superior multivariate techniques such as structural equation modeling (SEM) over traditional univariate tests. So, it would be particularly useful to employ SEM in future research to test some causal links between brand management-performance. A further limitation includes the use of some short scales with few items used in the study to measure the BMPs. Even though studies have shown that short scales are almost as good as long scales in capturing variation (Gogol et al. 2014), we admit that, in general, longer scales have a better reliability. The study should, therefore, be regarded as exploratory and be used as a basis for further deepened research with relatively larger data sets.

\section{References}

Aaker, D.A. (1991): Managing brand equity. New York: Free Press.

Abimbola, T./Kocak, A. (2007): Brand, organization identity and reputation: SMEs as expressive organizations, in: Qualitative Market Research: An International Journal, 10, 4, 416-430.

Anderson, J.C./Gerbing, D.W. (1988): Structural equation modeling in practice: A review and recommended two-step approach, in: Psychological Bulletin, 103, 3, 411-423.

Andriopoulos, C./Gotsi, M. (2000): Benchmarking brand management in the creative industry, in: Benchmarking: An International Journal, 7, 5, 360-372.

Anees-ur-Rehman, M./Wong, H.Y./Hossain, M. (2016): The progression of brand orientation literature in twenty years: A systematic literature review, in: Journal of Brand Management, 23, 6, 612-630.

Anil, I./Tatoglu, E./Ozkasap, G. (2014): Ownership and market entry mode choices of emerging country multinationals in a transition country: Evidence from Turkish 
multinationals in Romania, in: Journal for East European Management Studies, 19, 4, 413-452.

Armstrong, J.S./Overton, T.S. (1977): Estimating non-response bias in mail surveys, in: Journal of Marketing Research, 14, 3, 396-402.

Arthurs, J.D./Busenitz, L.W. (2006): Dynamic capabilities and venture performance: The effects of venture capitalists, in: Journal of Business Venturing, 21, 2, 195-215.

Baumgarth, C. (2010): "Living the brand": Brand orientation in the business-to-business sector, in: European Journal of Marketing, 44, 5, 653-671.

Berghman, L./Matthyssens, P./Vandenbempt, K. (2006): Building competences for new customer value creation: An exploratory study, in: Industrial Marketing Management, $35,8,961-973$.

Berthon, P./Ewing, M./Napoli, J. (2008): Brand management in small to medium-sized enterprises, in: Journal of Small Business Management, 46, 1, 27-45.

Brïdson, K./Evans, J. (2004): The secret to a fashion advantage is brand orientation, in: International Journal of Retail \& Distribution Management, 32, 8, 403-411.

Bruton, G./Lau, C.-M. (2008): Asian management research: Status today and future outlook, in: Journal of Management Studies, 45, 3, 636-659.

Burgess, S.M./Steenkamp, J-B.E.M. (2006): Marketing renaissance: How research in emerging markets advances marketing science and practice, in: International Journal of Research in Marketing, 23, 4, 337-356.

Capon, N./Berthon, P./Hulbert, J.M./Pitt, L.F. (2001): Brand custodianship: A new primer for senior managers, in: European Management Journal, 19, 3, 215-227.

Chen, X./Lam, L.W./Zou, H. (2011): Antecedents and performance consequences of integrated brand management in China: An exploratory study, in: Journal of Global Marketing, 24, 2, 167-180.

Çifci, S./Ekinci, Y./Whyatt, G./Japutra, A./Molinillo, S./Siala, H. (2016): A cross validation of consumer-based brand equity models: Driving customer equity in retail brands, in: Journal of Business Research, 69, 9, 3740-3747. 
Demirbag, M./Collings, D.G./Tatoglu, E./Mellahi, K./Wood, G. (2014): High-performance work systems and organizational performance in emerging economies: Evidence from MNEs in Turkey, in: Management International Review, 54, 3, 325-359.

De Jong, J.P./Marsili, O. (2006): The fruit flies of innovations: A taxonomy of innovative small firms, in: Research Policy, 35, 2, 213-229.

Déniz, M.D.L.C.D./Suárez, M.K.C. (2005): Corporate social responsibility and family business in Spain, in: Journal of Business Ethics, 56, 1, 27-41.

Douglas, S.P.,/Craig, C.S./Nijssen, E. (2001): Executive insights: Integrating branding strategy across markets: Building international brand architecture, in: Journal of International Marketing, 9, 2, 97-114.

Doyle, P. (1989): Building successful brands: The strategic options, in: Journal of Marketing Management, 5, 1, 77-95.

Dunes, M./Pras, B. (2013): Practices in the brand management system: Identification and considerations for five business sectors, in: Journal of Product \& Brand Management, $22,7,444-461$.

Duysters, G./Jacob, J./Lemmens, C./Jintian, Y. (2009): Internationalization and technological catching up of emerging multinationals: A comparative case study of China's Haier group, in: Industrial and Corporate Change, 18, 2, 325-349.

Ellis, P.D. (2006): Market orientation and performance: A meta-analysis and cross-national comparisons, in: Journal of Management Studies, 43, 5, 1089-1107.

Ellonen, H.K./Wikström, P./Jantunen, A. (2009): Linking dynamic-capability portfolios and innovation outcomes, in: Technovation, 29, 11, 753-762.

Enderwick, P. (2009): Large emerging markets (LEMs) and international strategy, in: International Marketing Review, 26, 1, 7-16.

Erdogmus, I./Bodur, M./Yilmaz, C. (2010): International strategies of emerging market firms: Standardization in brand management revisited, in: European Journal of Marketing, 44, 9/10, 1410-1436. 
Erguncu, S./Yildirim, G. (2014): How consumer mindset response and long-term marketing effectiveness differ in emerging vs mature markets in: Wang, C.L. (Ed.) Brand management in emerging markets: Theories and practices, IGI Global.

Ewing, M.T./Napoli, J. (2005): Developing and validating a multidimensional nonprofit brand orientation scale, in: Journal of Business Research, 58, 6, 841-853.

Gogol, K./Brunner, M./Goetz, T./Martin, R./Ugen, S./Keller, U./ Fischbach, A./Preckel, F. (2014): “My questionnaire is too long!" The assessments of motivational-affective constructs with three-item and single-item measures, in: Contemporary Educational Psychology, 39, 3, 188-205.

Gromark, J./Melin, F. (2011): The underlying dimensions of brand orientation and its impact on financial performance, in: Journal of Brand Management, 18, 6, 394-410.

Harrigan, K.R. (1985): An application of clustering for strategic group analysis, in: Strategic Management Journal, 6, 1, 55-73.

Heding, T./Knudtzen, C./Bjerre, M. (2008): Brand management: Theory and practice. London: Routledge.

Helfat, C.E./Winter, S.G. (2011): Untangling dynamic and operational capabilities: Strategy for the (N) ever-changing world, in: Strategic Management Journal, 32, 11, 1243-1250.

Hilmersson, M./Jansson, H. (2012): Reducing uncertainty in the emerging market entry process: on the relationship among international experiential knowledge, institutional distance, and uncertainty, in: Journal of International Marketing, 20, 4, 96-110.

Hirvonen, S./Laukkanen, T./Reijonen, H. (2013): The brand orientation-performance relationship: An examination of moderation effects, in: Journal of Brand Management, $20,8,623-641$.

Jit Singh Mann, B./Kaur, M. (2013): Exploring branding strategies of FMCG, services and durables brands: Evidence from India, in: Journal of Product \& Brand Management, 22, $1,6-17$.

Kearney, C. (2012): Emerging markets research: Trends, issues and future directions, in: Emerging Markets Review, 13, 2, 159-183.

Keller, K.L. (2000): The brand report card, in: Harvard Business Review, 78, 1, 147-157. 
Keller, K.L./Lehman, D.R. (2006): Brands and branding: Research findings and future priorities, in: Marketing Science, 25, 6, 740-759.

Keller, K.L./Lehman, D.R. (2009): Assessing long-term brand potential, in: Journal of Brand Management, 17, 1, 6-17.

Ketchen, D.J./Shook, C.L. (1996): The application of cluster analysis in strategic management research: An analysis and critique, in: Strategic Management Journal, 17, 6, 441-458.

Ketchen, D.J./Combs, J.G./Russell, C.J./Shook, C./Dean, M.A./Runge, J./Lohrke, F.T./Naumann, S.E./Haptonstahl, D.E./Baker, R./Beckstein, B.A./Handler, C./Honig, H./Lamoureux, S. (1997): Organizational configurations and performance: A metaanalysis. Academy of Management Journal, 40, 1, 223-240.

Khanna, T./Palepu, K.G./Sinha, J. (2005): Strategies that fit emerging markets, in: Harvard Business Review, June, 4-18.

King, C./So, K.K.F./Grace, D. (2013): The influence of service brand orientation on hotel employees' attitude and behaviors in China, in: International Journal of Hospitality Management, 34, 172-180.

Laukkanen, T./Nagy, G./Hirvonen, S./Reijonen, H./Pasanen, M. (2013): The effect of strategic orientations on business performance in SMEs: A multigroup analysis comparing Hungary and Finland, in: International Marketing Review, 30, 6, 510-535.

Lee, C./Baek, I./Park, S./Lee, J. (2008): The impact of the brand management system on brand performance in $\mathrm{B}-\mathrm{B}$ and $\mathrm{B}-\mathrm{C}$ environments, in: Industrial Marketing Management, 37, 7, 848-855.

Leiponen, A./Drejer, I. (2007): What exactly are technological regimes?: Intra-industry heterogeneity in the organization of innovation activities, in: Research Policy, 36, 8, $1221-1238$

Li, J.J./Zhou, K.Z. (2010): How foreign firms achieve competitive advantage in the Chinese emerging economy: Managerial ties and market orientation, in: Journal of Business Research, 63, 8, 856-862.

London, T./Hart, S.L. (2004): Reinventing strategies for emerging markets: Beyond the transnational model, in: Journal of International Business Studies, 35, 5, 350-370. 
Louro, M.J./Cunha, P.V. (2001): Brand management paradigms, in: Journal of Marketing Management, 17, 7-8, 849-875.

Malik, O.R./Kotabe, M. (2009): Dynamic capabilities, government policies, and performance in firms from emerging economies: Evidence from India and Pakistan, in: Journal of Management Studies, 46, 3, 421-450.

Matanda, T./Ewing, M.T. (2012): The process of global brand strategy development and regional implementation, in: International Journal of Research in Marketing, 29, 1, 512.

Merrilees, B./Rundle-Thiele, S./Lye, A. (2011): Marketing capabilities: Antecedents and implications for B2B SME performance, in: Industrial Marketing Management, 40, 3, 368-375.

Meyer, K.E./Tran, Y.T.T. (2006): Market penetration and acquisition strategies for emerging economies, in: Long Range Planning, 39, 2, 177-197.

Morgan, N.A. (2012): Marketing and business performance, in: Journal of the Academy of Marketing Science, 40, 1, 102-119.

Morgan, N.A./Slotegraaf, R.J./Vorhies, D.W. (2009): Linking marketing capabilities with profit growth, in: International Journal of Research in Marketing, 26, 4, 284-293.

Napoli, J. (2006): The impact of nonprofit brand orientation on organizational performance, in: Journal of Marketing Management, 22, 7-8, 673-694.

Newbert, S. (2007): Empirical research on the resource-based view of the firm: An assessment and suggestions for future research, in: Strategic Management Journal, 28, $2,121-146$.

Ng, S.C./Zhao, X./Fan, X./Rungtusanatham, J.M. (2014): TQM and brand-building by Chinese original brand manufacturers: Impact on business performance, in: International Journal of Production Research, 52, 3, 825-846.

Nunnally, J.C. (1978): Psychometric theory (2nd Ed.). New York: McGraw-Hill.

Omar, M./Williams Jr., R.L./Lingelbach, D. (2009): Global brand market-entry strategy to manage corporate reputation, in: Journal of Product \& Brand Management, 18, 3, 177187. 
Pitt, L./Napoli, J./Van Der Merwe, R. (2003): Managing the franchised brand: The franchisees' perspective, in: Journal of Brand Management, 10, 6, 411-420.

Protogerou, A./Caloghirou, Y./Lioukas, S. (2012): Dynamic capabilities and their indirect impact on firm performance, in: Industrial and Corporate Change, 21, 3, 615-647.

Reijonen, H. (2010): Do all SMEs practise same kind of marketing?, in: Journal of Small Business and Enterprise Development, 17, 2, 279-293.

Reijonen, H./Hirvonen, S./Nagy, G./Laukkanen, T./Gabrielsson, M. (2015): The impact of entrepreneurial orientation on B2B branding and business growth in emerging markets, in: Industrial Marketing Management, 51, 35-46.

Santos-Vijande, M.L./del Río-Lanza, A.B./Suárez-Álvarez, L./Díaz-Martín, A.M. (2013): The brand management system and service firm competitiveness, in: Journal of Business Research, 66, 2, 148-157.

Schultz, D./Barnes, B.E. (1999): Strategic brand communication campaigns. Chicago: NTC Business Books.

Sheth, J. (2011): Impact of emerging markets on marketing: Rethinking existing perspectives and practices, in: Journal of Marketing, 75, 4, 166-182.

Sinkula, J.M. (1994): Market information processing and organizational learning, in: Journal of Marketing, 58, 1, 35-45.

Srivastava, R.K./Shervani, T.A./Fahey, L. (1998): Market-based assets and shareholder value: A framework for analysis, in: Journal of Marketing, 62, 1, 2-18.

Tatoglu, E./Glaister, A.J./Demirbag, M. (2016): Talent management motives and practices in an emerging market: A comparison between MNEs and local firms, in: Journal of World Business, 51, 2, 278-293.

Teece, D.J./Pisano, G./Shuen, A. (1997): Dynamic capabilities and strategic management, in: Strategic Management Journal, 18, 7, 509-533.

Teece, D.J. (2007): Explicating dynamic capabilities: the nature and micro-foundations of (sustainable) enterprise performance, in: Strategic Management Journal, 28, 13, 13191350. 
Tsai, H.T./Eisingerich, A.B. (2010): Internationalization strategies of emerging markets firms, in: California Management Review, 53, 1, 114-135.

Türkyilmaz, A./Özkan, C. (2007): Development of a customer satisfaction index model: An application to the Turkish mobile phone sector, in: Industrial Management \& Data Systems, 107, 5, 672-687.

Urde, M. (1999): Brand orientation: A mindset for building brands into strategic resources, in: Journal of Marketing Management, 15, 1-3, 117-133.

Urde, M./Baumgarth, C./Merrilees, B. (2013): Brand orientation and market orientation from alternatives to synergy, in: Journal of Business Research, 66, 1, 13-20.

Walters, P.G.P./Samiee, S. (2003): Executive insights: Marketing strategy in emerging markets: The case of China, in: Journal of International Marketing, 11, 1, 97-106.

Winter, S.G. (2003): Understanding dynamic capabilities, in: Strategic Management Journal, 24, 10, 991-995.

Wong, H.Y./Merrilees, B. (2008): The performance benefits of being brand orientated, in: Journal of Product \& Brand Management, 17, 6, 372-383.

Wong, T.L./Wickham, M.D./Hecker, R. (2013): The strategic management of brand equity in emerging markets, in: ANZAM: Managing on the Edge, 1, 1-21.

Wu, L.Y. (2007): Entrepreneurial resources, dynamic capabilities and start-up performance of Taiwan's high-tech firms, in: Journal of Business Research, 60, 5, 549-555.

Xie, H.Y./Boggs, D.J. (2006): Corporate branding versus product branding in emerging markets, in: Marketing Intelligence and Planning, 24, 4, 347-364.

Yeung, M./Ramasamy, B. (2008): Brand value and firm performance nexus: Further empirical evidence, in: Journal of Brand Management, 15, 5, 322-335.

Zahra, S./Sapienza, H./Davidsson, P. (2006): Entrepreneurship and dynamic capabilities: A review, model and research agenda, in: Journal of Management Studies, 43, 4, 917-955.

Zollo, M./Winter, S.G. (2002): Deliberate learning and the evolution of dynamic capabilities, in: Organization Science, 13, 3, 339-351. 
Zott, C. (2003): Dynamic capabilities and the emergence of intraindustry differential firm performance: Insights from a simulation study, in: Strategic Management Journal, 24, 2, 97-125.

Table 1: Characteristics of the sample

\begin{tabular}{|l|c|c|}
\hline Sample characteristics & No & $\%$ \\
\hline Respondent type & & \\
\hline General/deputy general manager & 84 & 37.5 \\
\hline Product/brand manager & 73 & 32.6 \\
\hline Planning manager & 17 & 7.6 \\
\hline Other senior managers & 50 & 22.3 \\
\hline Ownership pattern & & \\
\hline Local & 161 & 71.9 \\
\hline Foreign & 63 & 28.1 \\
\hline Firm size (number of employees) & & \\
\hline SMEs (50 to 249) & 59 & 26.3 \\
\hline Large size (>250) & 165 & 73.7 \\
\hline Age (years of operation) & & \\
\hline Young firms ( Equal or less than 10) & 30 & 13.4 \\
\hline Middle age firms (11 to 20) & 62 & 27.7 \\
\hline Mature firms (More than 20) & 132 & 58.9 \\
\hline Sector of operation & & \\
\hline Automotive, electronics and electrical equipment & 24 & 10.7 \\
\hline Food, leather, wood and paper & 48 & 21.4 \\
\hline Textile and apparel & 35 & 15.7 \\
\hline Other manufacturing & 34 & 15.2 \\
\hline Banking and financial services & 22 & 9.8 \\
\hline Trade and hospitality & 24 & 10.7 \\
\hline Other services & 37 & 16.5 \\
\hline Total & $\mathbf{2 2 4}$ & $\mathbf{1 0 0}$ \\
\hline
\end{tabular}


Table 2: Brand management practices: Standardized loadings and AVE

Brand Management Practices (BMPs)

\begin{tabular}{|c|c|c|c|c|}
\hline \begin{tabular}{|c|}
$\begin{array}{c}\text { Standardized } \\
\text { loadings }\end{array}$ \\
\end{tabular} & Mean & S.D. & AVE & $\begin{array}{c}\text { Cronbach } \\
\boldsymbol{\alpha}\end{array}$ \\
\hline 0.72 & 4.50 & 0.66 & 0.51 & 0.75 \\
\hline 0.79 & 4.46 & 0.73 & & \\
\hline 0.62 & 4.50 & 0.78 & & \\
\hline
\end{tabular}

BMP 1: Brand delivers benefits customers truly desire.

1. Attempt to uncover unmet consumer needs and wants.

2. Focus on maximizing our customers' product and service experiences.

3. Have a system in place for getting customers' comments to the people who can effect/implement change.

BMP 2: Brand stays relevant.

4. Invest adequate resources in product improvements that provide better value to our customers.

5. Keep "in touch" with our customers' tastes.

0.81

4.23

0.87

0.60

0.75

\section{BMP 3: Pricing strategies based on perceptions of value.}

9. Have a system in place to monitor customers' perceptions of brand value.

10. Estimate how much value our customers believe the brand adds to our product.

\section{BMP 4: Brand is properly positioned.}

11. Establish "points-of-parity" for our brands that are necessary to simply compete in the product/service category (that is, identify the attributes/benefits that a brand must possess in order to just compete in a category).

12. Establish "points-of-parity" for our brands that negate the advantages our competitors attempt to achieve in the product/service category.

13. Establish unique "points-of-difference" for our brands that provide us with a competitive advantage in the product/service category (that is, identify the brand attributes/benefits on which we are clearly superior).

\section{BMP 5: Brand is consistent.}

14. Develop marketing programs that do not send conflicting messages about our brands to our target audience.

15. Adjust the brand's marketing program to keep current and abreast with changes in consumer tastes.

0.74

$4.45 \quad 0.80$

0.83

0.80

\begin{tabular}{|l|l|}
\hline 3.94 & 1.1 \\
\hline 4.10 & 0.8
\end{tabular}

\begin{tabular}{|l|l|l|}
\hline 1.11 & 0.67 & 0.79 \\
\hline 0.86 & & \\
\hline
\end{tabular}

\section{BMP 6: Brand portfolio and hierarchy make sense.}

16. Have a corporate brand that creates a seamless umbrella for all the brands in our portfolio.

17. Ensure that the brands in our portfolio target specific, well-defined segments, which do not overlap with one another.

18. Ensure that brands in our portfolio fully maximize market coverage.

19. Create a brand hierarchy that is well thought out and well understood by our staff.

BMP 7: Brand uses full repertoire of marketing activities to build equity.

21. Implement integrated "push and pull" marketing activities to target both distributors and customers.

22. Ensure that brand managers are aware of all of the marketing activities that involve their brands.

23. Ensure that all people involved in managing the marketing activities for a brand are aware of one another.

24. Capitalize on the unique capabilities of each communication tool (that is, advertising, PR, sales promotion, etc.) while ensuring that the meaning of the brand is consistently represented.

\begin{tabular}{|l|l|l|l|l|}
\hline 0.83 & 4.17 & 0.92 & 0.58 & 0.80 \\
\hline 0.70 & 3.87 & 1.06 & & \\
\hline 0.73 & 4.29 & 0.87 & & \\
\hline
\end{tabular}

\begin{tabular}{|l|l|l|l|l|l|}
\hline 0.75 & 4.08 & 1.02 & 0.58 & 0.72 \\
\hline 0.77 & 4.00 & 0.98 & & \\
\hline
\end{tabular}

\begin{tabular}{|l|l|l|l|l|l|}
\hline 0.66 & 4.25 & 1.02 & 0.57 & 0.83 \\
\hline & 0.84 & 4.10 & 0.90 & & \\
\hline & 0.75 & 4.37 & 0.79 & & \\
\hline
\end{tabular}

\begin{tabular}{|l|l|l|l|l|l|}
\hline 0.74 & 4.16 & 0.94 & 0.60 & 0.84 \\
\hline & 0.86 & 4.29 & 0.90 & & \\
\hline & 0.79 & 4.25 & 0.86 & & \\
\hline
\end{tabular}


Table 2: (continued)

\begin{tabular}{|c|c|c|c|c|c|}
\hline Brand Management Practices (BMPs) & \begin{tabular}{|c|}
$\begin{array}{c}\text { Standardized } \\
\text { loadings }\end{array}$ \\
\end{tabular} & Mean & S.D. & AVE & $\begin{array}{c}\text { Cronbach } \\
\boldsymbol{\alpha}\end{array}$ \\
\hline \multicolumn{6}{|l|}{ BMP 8: Brand managers understand what the brand means to consumers. } \\
\hline $\begin{array}{l}\text { 25. Develop detailed knowledge of what customers dislike about our } \\
\text { brands. }\end{array}$ & 0.81 & 4.05 & 0.91 & 0.60 & 0.88 \\
\hline $\begin{array}{l}\text { 26. Develop detailed knowledge of what customers like about our } \\
\text { brands. }\end{array}$ & 0.80 & 4.16 & 0.82 & & \\
\hline $\begin{array}{l}\text { 27. Develop knowledge of the core associations that people make with } \\
\text { our brands, whether intentionally created by our company or not. }\end{array}$ & 0.77 & 3.83 & 0.94 & & \\
\hline 28. Create detailed, research-driven portraits of target customers. & 0.74 & 3.99 & 0.95 & & \\
\hline $\begin{array}{l}\text { 29. Outline customer-driven boundaries for brand extensions and } \\
\text { guidelines for marketing programs and activities. }\end{array}$ & 0.79 & 3.93 & 1.01 & & \\
\hline \multicolumn{6}{|l|}{ BMP 9: Brand is given proper support and it is sustained over the long run. } \\
\hline $\begin{array}{l}\text { 30. Develop a good understanding of the successes and failures of our } \\
\text { brand's marketing program before it is changed. }\end{array}$ & 0.84 & 4.22 & 0.90 & 0.59 & 0.80 \\
\hline $\begin{array}{l}\text { 31. Provide our brands with sufficient research and development } \\
\text { support. }\end{array}$ & 0.83 & 4.13 & 0.93 & & \\
\hline $\begin{array}{l}\text { 32. Resist the temptation to cut back marketing support for the brand in } \\
\text { reaction to a downturn in the market or a slump in sales. }\end{array}$ & 0.61 & 3.97 & 0.95 & & \\
\hline \multicolumn{6}{|l|}{ BMP 10: Company monitors sources of brand equity. } \\
\hline $\begin{array}{l}\text { 33. Create a brand charter that defines the meaning and equity of the } \\
\text { brand and how it should be treated. }\end{array}$ & 0.78 & 3.52 & 1.32 & 0.60 & 0.88 \\
\hline 34. Conduct periodic brand audits to assess the "health" of our brands. & 0.84 & 3.71 & 1.25 & & \\
\hline $\begin{array}{l}\text { 35. Conduct routine tracking studies to evaluate current market } \\
\text { performance of our brands. }\end{array}$ & 0.76 & 3.91 & 1.06 & & \\
\hline $\begin{array}{l}\text { 36. Regularly distribute brand equity reports, which summarize all } \\
\text { relevant research and information, to marketers to assist them in making } \\
\text { decisions. }\end{array}$ & 0.80 & 3.74 & 1.18 & & \\
\hline $\begin{array}{l}\text { 37. Assign explicit responsibility to an individual within the organization } \\
\text { for monitoring and preserving brand equity. }\end{array}$ & 0.68 & 3.84 & 1.20 & & \\
\hline
\end{tabular}


Table 3: Discriminant validity calculation - difference in chi-square values between pairs of latent constructs (for one degree of freedom)

\begin{tabular}{|l|c|c|c|c|c|c|c|c|c|c|}
\hline Brand management practices & BMP 1 & BMP 2 & BMP 3 & BMP 4 & BMP 5 & BMP 6 & BMP 7 & BMP 8 & BMP 9 & BMP 10 \\
\hline BMP 1 & - & 92.5 & 97.4 & 81.0 & 88.36 & 83.6 & 125.4 & 93.8 & 84.27 & 60.4 \\
\hline BMP 2 & & - & 51.2 & 44.8 & 47.1 & 46.1 & 59.6 & 52.7 & 50.02 & 22.4 \\
\hline BMP 3 & & & - & 31.8 & 27.5 & 41.3 & 63.7 & 48.1 & 40.6 & 18.3 \\
\hline BMP 4 & & & & - & 31.9 & 34.7 & 57.6 & 41.8 & 32.4 & 10.7 \\
\hline BMP 5 & & & & & - & 27.1 & 45.8 & 35.5 & 32.11 & 11.9 \\
\hline BMP 6 & & & & & & - & 59.6 & 39.5 & 35.4 & 15.5 \\
\hline BMP 7 & & & & & & & - & 60.5 & 32.9 & 15.7 \\
\hline BMP 8 & & & & & & & & - & 31.4 & 15.5 \\
\hline BMP 9 & & & & & & & & & - & 12.2 \\
\hline BMP 10 & & & & & & & & & & - \\
\hline
\end{tabular}

Table 4: Final cluster centers for each of the ten BMPs

\begin{tabular}{|l|c|c|c|}
\hline \multirow{2}{*}{ Brand management practices } & \multicolumn{3}{|c|}{ Clusters } \\
\cline { 2 - 4 } & Low-BMP & Medium-BMP & High-BMP \\
\hline BMP 1: Brand delivers benefits customers truly desire. & 3.81 & 4.38 & 4.80 \\
\hline BMP 2: Brand stays relevant. & 3.27 & 4.23 & 4.78 \\
\hline BMP 3: Pricing strategies based on perceptions of value. & 2.70 & 3.82 & 4.65 \\
\hline BMP 4: Brand is properly positioned. & 3.00 & 3.90 & 4.66 \\
\hline BMP 5: Brand is consistent. & 2.90 & 3.74 & 4.68 \\
\hline BMP 6: Brand portfolio and hierarchy make sense. & 3.04 & 4.01 & 4.75 \\
\hline BMP 7: Brand uses full repertoire of marketing activities to build equity. & 3.05 & 4.05 & 4.72 \\
\hline BMP 8: Brand managers understand what the brand means to consumers. & 2.87 & 3.72 & 4.58 \\
\hline BMP 9: Brand is given proper support and it is sustained over the long run. & 2.90 & 3.99 & 4.64 \\
\hline BMP 10: Company monitors sources of brand equity. & 2.17 & 3.52 & 4.44 \\
\hline Percentage of the firms in each cluster & $15 \%$ & $40 \%$ & $45 \%$ \\
\hline
\end{tabular}

Table 5: Results of the ANOVA for clusters generated through K-means analysis

\begin{tabular}{|l|c|c|c|c|c|}
\hline \multirow{2}{*}{} & \multicolumn{2}{|c|}{ Cluster } & \multicolumn{2}{c|}{ Error } & \multirow{2}{*}{ F-value } \\
\cline { 2 - 5 } & Mean Square & d.f. & Mean Square & d.f. & \\
\hline BMP 1: Brand delivers benefits customers truly desire. & 12.03 & 2 & 0.21 & 205 & $55.64^{*}$ \\
\hline BMP 2: Brand stays relevant. & 27.00 & 2 & 0.30 & 205 & $88.78^{*}$ \\
\hline BMP 3: Pricing strategies based on perceptions of value. & 46.36 & 2 & 0.30 & 205 & $153.21^{*}$ \\
\hline BMP 4: Brand is properly positioned. & 34.62 & 2 & 0.25 & 205 & $135.30^{*}$ \\
\hline BMP 5: Brand is consistent. & 42.30 & 2 & 0.36 & 205 & $115.18^{*}$ \\
\hline BMP 6: Brand portfolio and hierarchy make sense. & 35.78 & 2 & 0.19 & 205 & $184.82^{*}$ \\
\hline $\begin{array}{l}\text { BMP 7: Brand uses full repertoire of marketing activities to } \\
\text { build equity. }\end{array}$ & 33.34 & 2 & 0.19 & 205 & $168.93^{*}$ \\
\hline $\begin{array}{l}\text { BMP 8: Brand managers understand what the brand means to } \\
\text { consumers. }\end{array}$ & 38.07 & 2 & 0.23 & 205 & $163.67^{*}$ \\
\hline $\begin{array}{l}\text { BMP 9: Brand is given proper support and it is sustained } \\
\text { over the long run. }\end{array}$ & 35.68 & 2 & 0.22 & 205 & $155.80^{*}$ \\
\hline BMP 10: Company monitors sources of brand equity. & 62.19 & 2 & 0.36 & 205 & $168.70^{*}$ \\
\hline
\end{tabular}

$* p<0.001$ 
Table 6: Firm-specific characteristics and adoption of BMPs

\begin{tabular}{|l|c|c|c|}
\hline Firm-specific characteristics & Low-BMP & Medium-BMP & High-BMP \\
\hline Firm size $^{a}$ & & & \\
\hline SMEs & $8(26.7 \%)$ & $29(34.5 \%)$ & $15(16 \%)$ \\
\hline Large firms & $22(73.3 \%)$ & $55(65.5 \%)$ & $79(84 \%)$ \\
\hline Ownership pattern $^{b}$ & & & \\
\hline Locally-owned & $24(80 \%)$ & $66(78 \%)$ & $60(63 \%)$ \\
\hline Foreign-owned & $6(20 \%)$ & $18(22 \%)$ & $34(37 \%)$ \\
\hline$N=208$ & 30 & 84 & 94 \\
\hline
\end{tabular}

\section{Notes:}

${ }^{\mathrm{a}} \chi^{2}=8.27 ;$ d.f. $=2 ; \mathrm{p}<0.05$

${ }^{\mathrm{b}} \chi^{2}=5.78 ;$ d.f. $=2 ; \mathrm{p}<0.1$

Table 7: ANOVA test results

\begin{tabular}{|l|c|c|c|c|}
\hline Performance Dimensions & Group & Mean $^{\mathbf{a}}$ & S.D. & F-value \\
\hline Overall performance & Low-BMP & 3.64 & 0.46 & $35.36^{*}$ \\
& Medium-BMP & 3.99 & 0.48 & \\
& High-BMP & 4.44 & 0.49 & \\
\hline Brand performance & Low-BMP & 3.30 & 0.55 & $25.49^{*}$ \\
& Medium-BMP & 3.69 & 0.52 & \\
& High-BMP & 4.16 & 0.64 & \\
\hline
\end{tabular}

\section{Notes:}

$* \mathrm{p}<0.001$.

'The mean is the average on a scale of 1 ('definitely worse') to 5 ('definitely better').

Table 8: Post-hoc tests

\begin{tabular}{|l|c|c|c|c|c|}
\hline \multicolumn{5}{|c|}{ Multiple Comparisons } \\
\hline \multicolumn{2}{|l|}{ Dependent variable } & $\begin{array}{c}\text { (I) Cluster number } \\
\text { of cases }\end{array}$ & $\begin{array}{c}\text { (J) Cluster number } \\
\text { of cases }\end{array}$ & $\begin{array}{c}\text { Mean difference } \\
\text { (I-J) }\end{array}$ & $\begin{array}{c}\text { Std. } \\
\text { error }\end{array}$ \\
\hline \multirow{2}{*}{$\begin{array}{l}\text { Overall } \\
\text { performance }\end{array}$} & $\begin{array}{l}\text { Dunnett t } \\
(2-\text {-sided })\end{array}$ & High-BMP & Low-BMP & $0.79^{*}$ & 0.105 \\
\hline \multirow{2}{*}{$\begin{array}{l}\text { Brand } \\
\text { performance }\end{array}$} & $\begin{array}{l}\text { Dunnett t } \\
(2-\text {-sided })\end{array}$ & Medium-BMP & Low-BMP & $0.36^{*}$ & 0.106 \\
\cline { 3 - 6 } & & Medium-BMP & Low-BMP & $0.85^{*}$ & 0.132 \\
\hline
\end{tabular}

\section{Notes:}

$* \mathrm{p}<0.05$.

aDunnett t-tests treat one group as a control, and compare all other groups against it. 